\title{
Descriptive Regional Subanalysis of a Real-World Study in Patients with Type 2 Diabetes Treated with Gliclazide MR During Fasting: DIA-RAMADAN
}

\author{
Mohamed Hassanein - Saud Al Sifri - Shehla Shaikh - Syed Abbas Raza • \\ Javed Akram • Achmad Rudijanto - Inass Shaltout • Md. Fariduddin • \\ Wan Mohd Izani Bin Wan Mohamed · Fatheya Al Awadi • \\ Alexandra Durocher · Viviana Cortese - Thamer Alessa
}

Received: April 8, 2021 / Accepted: April 21, 2021 / Published online: May 11, 2021

(C) The Author(s) 2021

\section{ABSTRACT}

Introduction: To analyse the safety and effectiveness of gliclazide modified release (MR) in adults with type 2 diabetes mellitus participating in Ramadan from three geographically and

Supplementary Information The online version contains supplementary material available at https:// doi.org/10.1007/s13300-021-01067-1.

M. Hassanein · F. Al Awadi

Department of Endocrinology, Dubai Hospital, Dubai, United Arab Emirates

S. Al Sifri

Al Hada Military Hospital, Taif, Saudi Arabia

S. Shaikh

Department of Endocrinology, Saifee Hospital, Mumbai, Maharashtra, India

\section{S. A. Raza}

Shaukat Khanum Memorial Cancer Hospital and Research Center, Lahore, Pakistan

J. Akram

University of Health Sciences, Lahore, Pakistan

A. Rudijanto

Department of Internal Medicine, Faculty of Medicine, Brawijaya University/Dr., Saiful Anwar Hospital, Malang, Indonesia

I. Shaltout

Department of Internal Medicine, Faculty of

Medicine, Cairo University, Cairo, Egypt culturally different regions of the world included in the DIA-RAMADAN study.

Methods: DIA-RAMADAN was a real-world, observational, international, non-comparative study. The global study population was divided into three regional subgroups, with data gathered at inclusion 6-8 weeks prior to Ramadan (V0), during Ramadan (4.5 weeks) and 4-6 weeks after Ramadan (V1). Primary endpoint was the proportion of patients reporting $\geq 1$ symptomatic hypoglycaemic events

Md. Fariduddin

Department of Endocrinology, Bangabandhu Sheikh Mujib Medical University, Dhaka, Bangladesh

W. M. I. B. W. Mohamed

Department of Medicine, Hospital Universiti Sains Malaysia, Kota Bharu, Kelantan, Malaysia

W. M. I. B. W. Mohamed

School of Medical Sciences, Universiti Sains Malaysia (USM) Health Campus, Kubang Kerian, Kelantan, Malaysia
A. Durocher $(\bowtie) \cdot$ V. Cortese
Servier Global Medical and Patient Affairs-Diabetes, 35 rue de Verdun, 92284 Suresnes Cedex, France e-mail: Alexandra.durocher@servier.com
T. Alessa
Dasman Diabetes Institute, Kuwait City, Kuwait 
(HE), which were collected using a patient diary along with other adverse events.

Results: Patient numbers from the three regions were $n=564$ (46.5\%; Indian sub-continent), $n=354$ (29.1\%; Middle East) and $n=296$ (24.4\%; South-East Asia). Patient baseline characteristics, demographics, fasting habits and antidiabetic treatments varied between regions. There were similar proportions of symptomatic HE between regions, with no severe HE. Significant weight reductions were observed in all regions following Ramadan, along with reductions in $\mathrm{HbA}_{1 \mathrm{c}}$ and fasting plasma glucose.

Conclusion: These real-world study data indicate that gliclazide MR is safe and effective for management of type 2 diabetes during Ramadan in all three regions studied as part of DIARAMADAN.

Trial Registration: Clinicaltrials.gov identifier NCT04132934. 


\section{Infographic:}

\section{DiabetesTherapy} Descriptive Regional Subanalysis of a Real-World Study In Patients With Type 2
Diabetes Treated With Gliclazide MR During Fasting: DIA-RAMADAN

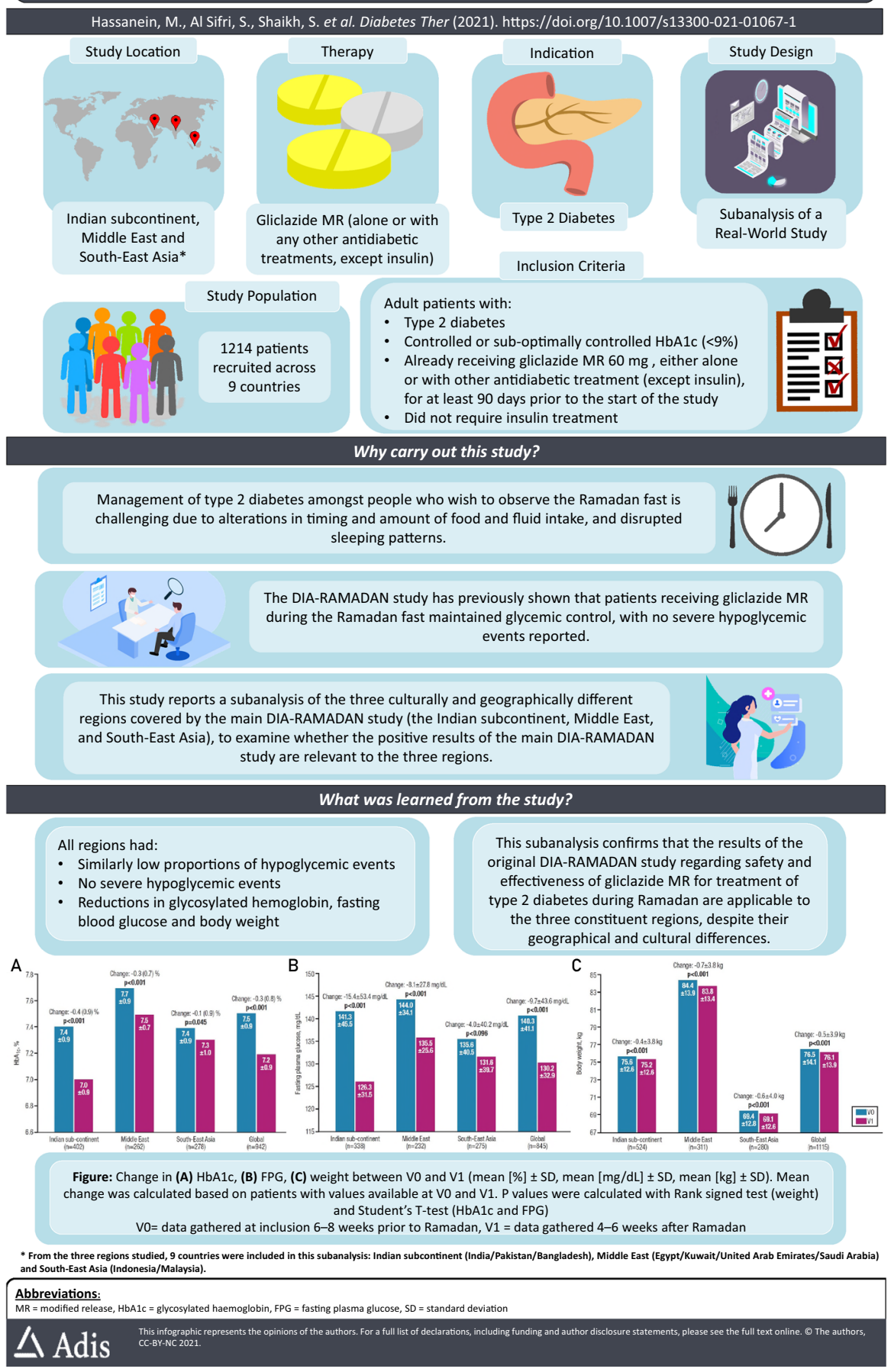

Keywords: Diabetes mellitus; Fasting; Gliclazide; Ramadan; Type 2 


\section{DIGITAL FEATURES}

This article is published with digital features, including a summary slide and infographic, to facilitate understanding of the article. To view digital features for this article go to https://doi. org/10.6084/m9.figshare.14453745.

\section{INTRODUCTION}

The number of patients with diabetes mellitus is predicted to grow over the next 25 years, with a global increase of up to $51 \%$ by 2045 [1]. Type 2 diabetes is the most common form of the disease, representing about $90 \%$ of cases [1].

Ramadan is one of the five pillars of Islam and involves a period of fasting (including abstention from food and fluid intake) from dawn to dusk throughout the ninth lunar month of the Islamic calendar. Although some patients with chronic diseases are amongst the groups that may be exempt from fasting, many people with diabetes still choose to fast as they consider it important to their health and wellbeing [2]. This can result in several risks for these people, including hypoglycaemia and hyperglycaemia due to reduced dosing of antidiabetic medication [3]. Other factors to consider include disrupted sleep patterns, meal timings and the type of food consumed while breaking fast [4].

The large global Muslim population means that it is important to understand how best to manage diabetes during Ramadan [5]. Based on this, the International Diabetes Federation (IDF) and Diabetes and Ramadan (DAR) International Alliance have published guidelines for management of diabetes during Ramadan [4].

Sulphonylureas are a group of antidiabetic medications that act by increasing insulin secretion by pancreatic beta cells [6]. This class of drugs has previously been associated with an increased risk of hypoglycaemia during fasting; however, more recent second-generation sulphonylureas are considered safe to use during fasting [6-10]. Gliclazide is a sulphonylurea that is available in both immediate release (IR) and modified release (MR) forms [11]. The MR formulation results in progressive release of the drug based on a once-daily dosing regimen, with evidence of a lower risk of hypoglycaemia compared with the sulpfonylurea glimepiride $[11,12]$. Both forms have previously been associated with a low instance of hypoglycaemia during the Ramadan fast versus other sulphonylureas [7, 10]. Recently published Ramadan guidelines consider people with type 2 diabetes treated with newer sulphonylureas, including gliclazide MR, as being at low risk of hypoglycaemic events during Ramadan fasting [13].

The DIA-RAMADAN study was an international, real-world, prospective observational study conducted in clinical centres from nine Asian and Middle Eastern countries, carried out to investigate the effectiveness and safety of gliclazide MR in people with type 2 diabetes mellitus who are fasting during Ramadan [14]. Patients were assessed at two study visits, one before and one after Ramadan. Glycaemic control was well maintained by the patients in this study, with a small decline in weight observed. Only $2.2 \%$ of patients reported one or more symptomatic hypoglycaemic events (HEs), and no severe HEs were reported.

In this descriptive subanalysis of DIARAMADAN, we present individual results from the three regions studied: the Indian subcontinent (India/Pakistan/Bangladesh), Middle East (Egypt/Kuwait/United Arab Emirates/Saudi Arabia) and South-East Asia (Indonesia/Malaysia), including baseline characteristics, safety and effectiveness (i.e. maintenance of glycaemic control) data. These regions of the world are culturally different, with different nutritional habits. Their location also results in different hours of fasting during Ramadan and means that weather conditions will vary between the regions. The aim of this study is therefore to examine whether the positive results observed in the DIA-RAMADAN study are relevant to each of these different subregions. Moreover, this subanalysis will add to the currently sparse data about Ramadan fasting in the three areas studied. 


\section{METHODS}

Details of the study design have previously been published [14]. Key methodological details are presented below.

\section{Study Design}

In brief, DIA-RAMADAN was a real-world, observational, non-comparative, international study including adult patients with type 2 diabetes and controlled or suboptimally controlled glycosylated haemoglobin $\left(\mathrm{HbA}_{1 \mathrm{c}}\right)(<9 \%)$, who had already been undergoing treatment with breakable gliclazide MR $60 \mathrm{mg}$ tablets for $\geq 90$ days prior to study start, and not requiring insulin treatment.

Two patient visits were planned as per IDFDAR Ramadan guidelines [4]: the first (V0) 6-8 weeks prior to Ramadan and the second (V1) 4-6 weeks following Ramadan. As previously detailed, the following information was gathered during V0: informed patient consent; patient demographics, lifestyle habits, physical activity levels, IDF-DAR risk classification and medical history. Study eligibility was assessed and a physical examination carried out. Advice was given regarding gliclazide intake during Ramadan; according to IDF-DAR guidelines, gliclazide MR should be administered during iftar (sunset meal). Patients used a diary to record any treatment changes, details of hypoglycaemic symptoms and adverse events.

At the second visit (V1), routine investigations were carried out, including glycaemic profile and laboratory values. Details regarding treatment adherence and nutritional habits during Ramadan (including adherence to fasting) were collected.

\section{Inclusion Criteria}

Inclusion and exclusion criteria have previously been presented in detail elsewhere [14]; in brief, adult patients with type 2 diabetes and controlled or sub-optimally controlled $\mathrm{HbA}_{1 \mathrm{c}}$ $(<9 \%)$ who were already receiving gliclazide MR $60 \mathrm{mg}$ for at least 90 days prior to the start of the study and did not require insulin treatment were included. The study was conducted in accordance with the Declaration of Helsinki. Approval was obtained from the following independent ethics committees or institutional review boards: Conscience Independent Ethics Committee (India, IRB00010059), Drug Regulatory Authority of Pakistan (F.No.03-01/2019-DD(PS)), Bangladesh Medical Research Council (BMRC/NREC/20162019/933(1-3)), Independent ethics Committees (Sains IRB00010568, Kebangsaan, not available and Malaya, MREC ID No. 2017528-5276) (Malaysia), Dubai Scientific Research Ethics Committee (UAE, DSREC-12/ 2018_14)), Dasman Institute Ethics Committee (Kuwait, RA/054/2019), Institutional Review Board King Fahad Medical City (Saudi Arabia, IRB00010471, FWA00018774), Ministry of Health (Egypt, not available) and Badan Pengawas Obat dan Makanan (Indonesia, BPOM128/NKT/III/2019). All patients provided informed written consent to participate in the study. The trial was registered on ClinicalTrials.gov (NCT04132934).

\section{Study Treatments}

Patients were treated with gliclazide MR $60 \mathrm{mg}$ oral tablets for $\geq 90$ days prior to the start of the study. Before Ramadan, gliclazide MR was taken at breakfast according to the Summary of Product Characteristics [15]. During Ramadan, physicians advised their patients to take their gliclazide MR following iftar. Any dose adjustments were at the investigator's discretion and based on routine practice and any relevant local guidelines. Treatment adherence was calculated as follows: (sum of number of intakes during Ramadan/sum of number of intakes to be taken during Ramadan) $\times 100$ [14]. Due to the realworld setting of the study, concomitant treatments were permitted at the investigator's discretion and new treatments were initiated if deemed beneficial for the patient, and not contra-indicated for use with gliclazide MR. 


\section{Study Endpoints}

The primary endpoint of the study was the proportion of patients with $\geq 1$ symptomatic HE (either suggestive or confirmed by a measured glucose concentration $\leq 3.9 \mathrm{mmol} / \mathrm{l}$ [16] . Secondary endpoints included change of $\mathrm{HbA}_{1 \mathrm{c}}$, FPG and weight between V0 and V1 as well as the proportion of patients with $\geq 1$ confirmed HE (asymptomatic or symptomatic). The proportion of patients with $\geq 1 \mathrm{HE}$ of any type and $\geq 1$ severe HE were also examined.

HEs were defined in this study according to the following criteria: confirmed asymptomatic HE-absence of typical hypoglycaemia symptoms (e.g. sweating, pallor, tremor, intense hunger, pounding heart, visual disturbance, drowsiness, weakness, dizziness, difficulty in concentrating, difficulty in speaking or writing, incoordination, unexplained behaviour or mood change, confusion, nausea or headache) but with a measured glucose concentration $\leq 70 \mathrm{mg} / \mathrm{dl} \quad(\leq 3.9 \mathrm{mmol} / \mathrm{l}) ; \quad$ confirmed symptomatic HE-presence of typical symptoms of hypoglycaemia and a measured glucose concentration $\leq 72 \mathrm{mg} / \mathrm{dl} \quad(\leq 4 \mathrm{mmol} / \mathrm{l})$; suggestive HE-presence of typical hypoglycaemic symptoms without a measured glucose concentration or a measurement of $>72 \mathrm{mg} / \mathrm{dl}$ ( $>4 \mathrm{mmol} / \mathrm{l}$ ); severe hypoglycaemia-symptoms of severe cognitive impairment and requiring third-party assistance for recovery.

\section{Adverse Events}

For all reported adverse events (AEs), possible relationship to the study drug, severity of the reported $\mathrm{AE}$ and outcome were assessed by the patient's physician. Details regarding reporting of AEs and definition of serious AEs are reported elsewhere [14]. MedDRA version 19.0 was used to code AEs.

\section{Statistical Analysis}

Paired Student's $T$ test was used to analyse differences in $\mathrm{HbA}_{1 \mathrm{c}}$ and FPG between V0 and V1. A ranked sign test was used to analyse the change in weight between V0 and V1. The threshold for statistical significance was defined as $P=0.05$.

Analyses were carried out using SAS software version 9.4 or higher (SAS Institute, Cary, NC, USA).

\section{RESULTS}

\section{Patient Demographics and Baseline Characteristics}

A total of 1214 patients were recruited across 9 countries. Patients were divided into subgroups based on three regions-Indian sub-continent (India/Pakistan/Bangladesh; $n=564, \quad 46.5 \%$ global study population), Middle East (Egypt/ Kuwait/United Arab Emirates/Saudi Arabia; $n=354,29.1 \%$ ) and South-East Asia (Indonesia/ Malaysia; $n=296,24.4 \%$ ). Details of the number of patients contributed by each country within regions are included as Supplementary Material.

Patient baseline characteristics and demographics are shown in Table 1. Patients from the Indian sub-continent were generally younger; $42.7 \%$ patients in this subgroup were 50 years or younger compared with $33.6 \%$ in the Middle East and $16.2 \%$ in South-East Asia. Patients in South-East Asia had a lower bodyweight compared with the other two regions. The mean gliclazide MR dose was higher in the Middle East, and more patients from the Middle East were treated with $90 \mathrm{mg}$ and $120 \mathrm{mg}$ doses of gliclazide MR. A higher proportion of patients in South-East Asia had arterial hypertension $(47.6 \%)$ vs. the Indian sub-continent $(38.7 \%)$ and the Middle East (21.5\%). Diabetic complications were generally similar among the subgroups, although diabetic neuropathy was more frequently encountered in the Middle East. A greater proportion of patients in South-East Asia were in the lowest IDF-DAR risk category.

Treatment adherence to gliclazide MR during Ramadan was high for each subgroup (Indian sub-continent: 99.4\%; Middle East: 99.9\%; South-East Asia: 99.1\%).

In the overall population, the most common combination partners for gliclazide MR were metformin (27\%), dipeptidyl peptidase 4 (DPP4) 
Table 1 Baseline characteristics

\begin{tabular}{|c|c|c|c|c|}
\hline Characteristic & $\begin{array}{l}\text { Indian sub-continent } \\
(n=564)\end{array}$ & $\begin{array}{l}\text { Middle East } \\
(n=354)\end{array}$ & $\begin{array}{l}\text { South-East Asia } \\
(n=296)\end{array}$ & $\begin{array}{l}\text { Global } \\
(n=1214)\end{array}$ \\
\hline Mean age $(\mathrm{SD})$, years & $51.8(10.8)$ & $54.4(10.3)$ & $58.0(8.7)$ & $54.1(10.5)$ \\
\hline \multicolumn{5}{|l|}{ Age groups, $n(\%)$} \\
\hline$<50$ years & $241(42.7)$ & $119(33.6)$ & $48(16.2)$ & $408(33.6)$ \\
\hline$\geq 50$ and $\leq 65$ years & $264(46.8)$ & $180(51.0)$ & $193(65.2)$ & $637(52.5)$ \\
\hline$>65$ years & $59(10.5)$ & $55(15.5)$ & $55(18.6)$ & $169(14.0)$ \\
\hline Female, $n(\%)$ & $253(44.9)$ & $153(43.2)$ & $143(48.3)$ & $549(45.2)$ \\
\hline $\begin{array}{l}\text { Mean disease duration }(\mathrm{SD}) \text {, } \\
\text { years }\end{array}$ & $5.5(6.2)$ & $5.5(5.2)$ & $5.3(4.9)$ & $5.4(5.7)$ \\
\hline BMI (SD), $\mathrm{kg} / \mathrm{m}^{2}$ & $28.5(4.0)$ & $30.1(4.2)$ & $26.7(4.1)$ & $28.4(4.3)$ \\
\hline Weight (SD), kg & $75.6(12.6)$ & $84.4(13.9)$ & $69.4(12.8)$ & $76.5(14.1)$ \\
\hline Mean $\mathrm{HbA}_{1 \mathrm{c}}(\mathrm{SD}), \%$ & $7.4(0.9)$ & $7.7(0.9)$ & $7.4(0.9)$ & $7.5(0.9)$ \\
\hline Mean FPG, mg/dl & $141.3(45.5)$ & $144.0(34.1)$ & $135.6(40.5)$ & $140.3(41.1)$ \\
\hline $\begin{array}{l}\text { Mean dose of gliclazide MR } \\
\text { (SD), mg }\end{array}$ & $69.8(24.9)$ & $84.0(28.6)$ & $69.9(24.8)$ & $74.0(26.8)$ \\
\hline \multicolumn{5}{|c|}{ Dose groups for gliclazide MR, $n(\%)$} \\
\hline $30 \mathrm{mg}$ & $33(5.9)$ & $12(3.4)$ & $16(5.4)$ & $61(5.0)$ \\
\hline $60 \mathrm{mg}$ & $413(73.2)$ & $167(47.2)$ & $218(73.6)$ & $798(65.7)$ \\
\hline $90 \mathrm{mg}$ & $19(3.4)$ & $55(15.5)$ & $10(3.4)$ & $84(7.0)$ \\
\hline $120 \mathrm{mg}$ & $99(17.6)$ & $120(33.9)$ & $52(17.6)$ & $271(22.3)$ \\
\hline $\begin{array}{l}\text { Established cardiovascular } \\
\text { disease, } n(\%)\end{array}$ & $14(2.5)$ & $38(10.7)$ & $25(8.4)$ & $77(6.3)$ \\
\hline Arterial hypertension, $n$ (\%) & $218(38.7)$ & $76(21.5)$ & $141(47.6)$ & $435(35.8)$ \\
\hline Dyslipidaemia, $n$ (\%) & $152(27.0)$ & $53(15.0)$ & $145(49.0)$ & $350(28.8)$ \\
\hline Diabetic nephropathy, $n$ (\%) & $2(0.4)$ & $4(1.1)$ & $3(1.0)$ & $3(1.0)$ \\
\hline Diabetic retinopathy, $n$ (\%) & $3(0.5)$ & $2(0.6)$ & $4(1.4)$ & $9(0.7)$ \\
\hline Diabetic neuropathy, $n$ (\%) & $34(6.0)$ & $42(11.9)$ & $9(3.0)$ & $85(7.0)$ \\
\hline \multicolumn{5}{|l|}{ Cardiovascular drugs, $n$ (\%) } \\
\hline Statin or ezetimibe & $193(34.2)$ & $66(18.6)$ & $154(52.0)$ & $413(34.0)$ \\
\hline ACEI or ARB & $85(15.1)$ & $28(7.9)$ & $66(22.3)$ & $179(14.7)$ \\
\hline Beta-blocker & $38(6.7)$ & $53(15)$ & $30(10.0)$ & $121(10.0)$ \\
\hline Antiplatelet agents & $55(9.8)$ & $22(6.2)$ & $33(11.0)$ & $110(9.1)$ \\
\hline Calcium channel blockers & $41(7.3)$ & $5(1.4)$ & $64(21.6)$ & $110(9.1)$ \\
\hline Diuretics & $22(3.9)$ & $7(2.0)$ & $13(4.4)$ & $42(3.5)$ \\
\hline
\end{tabular}


Table 1 continued

\begin{tabular}{|c|c|c|c|c|}
\hline Characteristic & $\begin{array}{l}\text { Indian sub-continent } \\
(n=564)\end{array}$ & $\begin{array}{l}\text { Middle East } \\
(n=354)\end{array}$ & $\begin{array}{l}\text { South-East Asia } \\
(n=296)\end{array}$ & $\begin{array}{l}\text { Global } \\
(n=1214)\end{array}$ \\
\hline \multicolumn{5}{|l|}{ Number of antidiabetic drugs, \% } \\
\hline 1 & 42.0 & 47.0 & 31.0 & 41.0 \\
\hline 2 & 25.0 & 20.0 & 51.0 & 30.0 \\
\hline$\geq 3$ & 33.0 & 33.0 & 18.0 & 29.0 \\
\hline \multicolumn{5}{|l|}{ Working status, \% } \\
\hline Active full-time worker & 37.2 & 35.0 & 30.4 & 35.0 \\
\hline Active part-time worker & 9.9 & 13.0 & 13.9 & 12.0 \\
\hline Non-active worker & 20.0 & 18.4 & 7.4 & 17.0 \\
\hline Student & 0.5 & 0 & 0 & 0.2 \\
\hline Retired & 7.8 & 22.0 & 28.4 & 17 \\
\hline Other & 24.5 & 6.8 & 19.9 & 18.2 \\
\hline \multicolumn{5}{|l|}{ Physical activity, \% } \\
\hline Sedentary & 36.9 & 31.6 & 36.1 & 35.0 \\
\hline Moderate & 56.6 & 52.5 & 55.4 & 55.0 \\
\hline Intermediate & 6.2 & 9.3 & 7.4 & 7.4 \\
\hline Intensive & 0.4 & 1.1 & 1.0 & 1.6 \\
\hline \multicolumn{5}{|l|}{ IDF-DAR risk category } \\
\hline Category 1: very high & 0.2 & 13 & 0 & 3.9 \\
\hline Category 2: high & 16.8 & 15.8 & 1.4 & 12.8 \\
\hline Category 3: moderate/low & 83.0 & 65.8 & 98.6 & 81.8 \\
\hline Patients advised not to fast, $\%$ & 24.3 & 38.1 & 8.4 & 24.5 \\
\hline
\end{tabular}

$A C E I$ angiotensin-converting enzyme 1 inhibitor, $A R B$ angiotensin receptor blocker, $B M I$ body mass index, $F P G$ fasting plasma glucose, $H b A_{1 c}$ glycosylated haemoglobin, IDF-DAR International Diabetes Federation-Diabetes and Ramadan, $M R$ modified release, $S D$ standard deviation

inhibitors $(16 \%)$ and sodium glucose cotransporter-2 (SGLT2) inhibitors (10\%) [14]. Fewer patients in South-East Asia had received three or more antidiabetic treatments $(18 \%)$ versus the Middle East and the Indian sub-continent (both $33 \%)$. The proportions of patients receiving combinations of antidiabetic medications for each region are shown in Fig. 1.

Overall, $82 \%$ of patients received a maximum of two antidiabetic treatments in SouthEast Asia versus $67 \%$ in patients from both the
Middle East and Indian sub-continent. SouthEast Asia included the highest proportion of patients treated with gliclazide $\mathrm{MR}+$ metformin (42.9\%). In the Indian sub-continent, a greater percentage of patients were treated with gliclazide MR + DPP4 inhibitors and gliclazide MR + SGLT2 inhibitors with or without other treatments $(22.3 \%$ and $11.5 \%$, respectively) compared with other regions (South-East Asia $8.1 \%$ and $4.7 \%$, respectively; Middle East $13.6 \%$ and $4.2 \%$, respectively). The highest instance of 


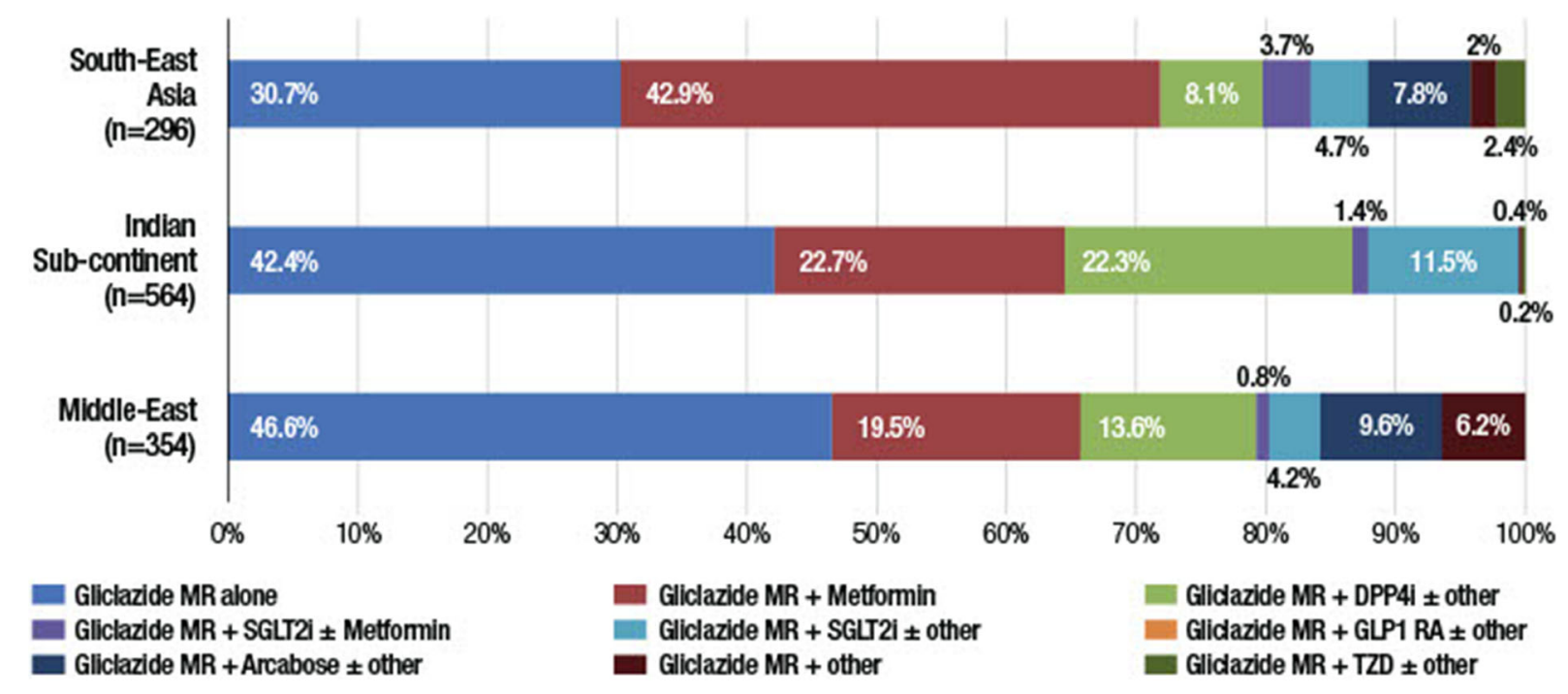

Fig. 1 Antidiabetic treatments in the three regions. DPP $4 i$ dipeptidyl peptidase 4 inhibitor, GLP1 RA glucagon-like peptide 1 receptor agonist, $S G L T-2 i$ sodium glucose cotransporter 2 inhibitor, $M R$ modified release, $T Z D$ thiazolidinedione

gliclazide MR monotherapy was observed in the Middle East (46.6\%).

\section{Fasting and Nutritional Habits During Ramadan}

All three regions had similar numbers of fasted days during Ramadan (Table 2). The mean fasted hours per day was highest in the Middle East $(15.8 \mathrm{~h})$ and lowest in South East Asia (13.7 h). In terms of meal type, the increase in carbohydrate intake was highest in South-East Asia, whereas the increase in fat intake was highest in patients from the Indian sub-continent. Rates of breaking fast were highest in the Indian subcontinent and lowest in South-East Asia; however, rates of breaking fast on $>3$ consecutive days were similarly low between subgroups.

The number of meals consumed per day decreased from nearly three meals per day outside Ramadan to slightly more than two per day during Ramadan in all three regions (Table 2). The number of snacks also reduced to less than one per day in all three regions.

\section{Safety Outcomes}

The proportion of patients reporting at least one symptomatic hypoglycaemic event during
Ramadan was generally low overall, with similar rates in all three regions (Table 3). Importantly, there were no severe hypoglycaemia events, and no gliclazide MR-related adverse events were noted in any of the three regions. A significant weight reduction was observed following Ramadan in all regions (Fig. 2a), with the greatest decrease observed in the Middle East (84.4 vs. $83.8 \mathrm{~kg}, P<0.001$ ).

\section{Changes in $\mathrm{HbA}_{1 \mathrm{c}}$ and FPG}

Mean $\mathrm{HbA}_{1 \mathrm{c}}$ decreased significantly in all three regions at V1 following Ramadan (Fig. 2b). The Indian subcontinent exhibited the greatest decrease between V0 and V1 (7.4 vs. $7.0 \%$, respectively, $P<0.001)$. Patients from this region also had the youngest population and a high proportion of patients (33\%) taking at least three antidiabetic medications, as described in Table 1. Mean FPG also decreased in all regions following Ramadan (Fig. 2c), although this change was not significant in South-East Asia (135.6 vs. $131.6 \mathrm{mg} / \mathrm{dl}, P=0.096$ ). 
Table 2 Fasting and dietary changes during Ramadan

\begin{tabular}{|c|c|c|c|c|}
\hline Characteristic & $\begin{array}{l}\text { Indian sub-continent } \\
(n=564)\end{array}$ & $\begin{array}{l}\text { Middle East } \\
(n=354)\end{array}$ & $\begin{array}{l}\text { South-East Asia } \\
(n=296)\end{array}$ & $\begin{array}{l}\text { Global } \\
(n=1214)\end{array}$ \\
\hline Days fasted during Ramadan, mean (SD) & $28(3.9)$ & $29.6(1.8)$ & $29.1(3.8)$ & $28.7(3.5)$ \\
\hline $\begin{array}{l}\text { Hours/day fasted during Ramadan, mean } \\
\text { (SD) }\end{array}$ & $14.7(1.6)$ & $15.8(1.1)$ & $13.7(0.9)$ & $14.7(1.5)$ \\
\hline $\begin{array}{l}\text { Patients who broke fast during Ramadan, } \\
n(\%)\end{array}$ & $312(55.3)$ & $143(40.4)$ & $39(13.2)$ & $494(40.7)$ \\
\hline $\begin{array}{l}\text { Patients who broke fast for more than } 3 \\
\text { consecutive days, } n(\%)\end{array}$ & $34(6.0)$ & $11(3.1)$ & $17(5.7)$ & $62(5.1)$ \\
\hline \multicolumn{5}{|l|}{ Dietary changes during Ramadan } \\
\hline More carbohydrate, $\%$ & 15.2 & 12.0 & 21.6 & 15.9 \\
\hline More proteins, $\%$ & 15.4 & 14.4 & 7.1 & 13.1 \\
\hline More fat, $\%$ & 20.0 & 6.0 & 9.8 & 13.4 \\
\hline Other change, $\%$ & 0.7 & 0.3 & 13.1 & 3.6 \\
\hline \multicolumn{5}{|c|}{ Average numbers of meals consumed per day (SD) } \\
\hline Outside Ramadan & $2.7(0.5)$ & $2.8(0.4)$ & $2.8(0.5)$ & $2.8(0.5)$ \\
\hline During Ramadan & $2.3(0.5)$ & $2.2(0.4)$ & $2.0(0.4)$ & $2.2(0.4)$ \\
\hline \multicolumn{5}{|c|}{ Average numbers of snacks consumed per day (SD) } \\
\hline Outside Ramadan & $1.5(0.9)$ & $1.0(0.8)$ & $1.3(1.0)$ & $1.3(0.9)$ \\
\hline During Ramadan & $0.7(0.8)$ & $0.9(0.7)$ & $1.0(0.7)$ & $0.8(0.8)$ \\
\hline
\end{tabular}

$S D$ standard deviation

Table 3 Proportion of patients with at least one hypoglycaemia event during Ramadan

\begin{tabular}{lllll}
\hline Characteristic & $\begin{array}{l}\text { Indian sub-continent } \\
(\boldsymbol{n}=\mathbf{5 6 4})\end{array}$ & $\begin{array}{l}\text { Middle East } \\
(\boldsymbol{n}=\mathbf{3 5 4})\end{array}$ & $\begin{array}{l}\text { South-East Asia } \\
(\boldsymbol{n}=\mathbf{2 9 6})\end{array}$ & $\begin{array}{l}\text { Global } \\
(\boldsymbol{n}=\mathbf{1 2 1 4})\end{array}$ \\
\hline $\begin{array}{l}\geq 1 \text { symptomatic hypoglycaemia event } \\
\text { (confirmed or not), } n \text { (\%) }\end{array}$ & $10(1.8)$ & $8(2.1)$ & $9(3.1)$ & $27(2.2)$ \\
$\begin{array}{l}\mathbf{1} \text { confirmed hypoglycaemia event } \\
\text { (symptomatic or not), } n \text { (\%) }\end{array}$ & $9(1.6)$ & $2(0.6)$ & $8(2.7)$ & $19(1.6)$ \\
$\geq 1$ severe hypoglycaemia event, $n$ & 0 & 0 & 0 & 0 \\
\hline
\end{tabular}

Symptomatic hypoglycaemia is defined as the presence of at least one of the following symptoms: sweating, pallor, tremor, intense hunger, pounding heart, visual disturbance, drowsiness, weakness, dizziness, difficulty in concentrating, difficulty in speaking or writing, incoordination, unexplained behaviour or mood change, confusion, nausea, headache; without (suggestive) or with (confirmed) a measurement of plasma glucose concentration $\leq 70 \mathrm{mg} / \mathrm{dl}$ ( $\leq 3.9 \mathrm{mmol} / \mathrm{l})$. Confirmed hypoglycaemia is defined as the proportion of patients with $\geq 1$ hypoglycaemia episode (symptomatic or not), confirmed with a measured plasma glucose concentration level $\leq 70 \mathrm{mg} / \mathrm{dl}(\leq 3.9 \mathrm{mmol} / \mathrm{l})$. Severe hypoglycaemia is defined as reported severe cognitive impairment requiring third-party assistance for recovery 
A

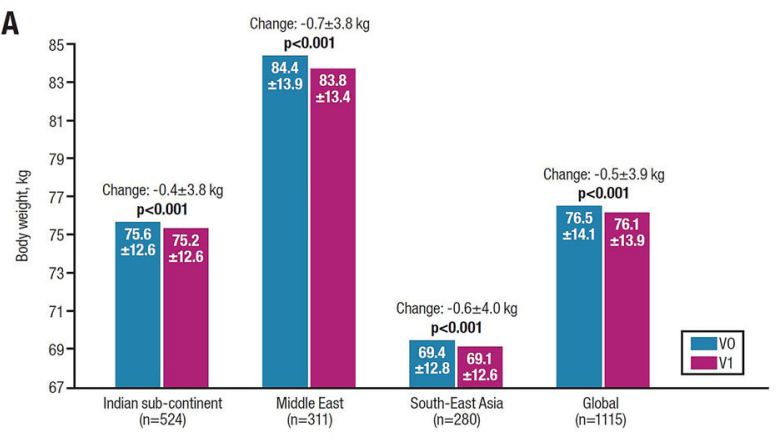

C

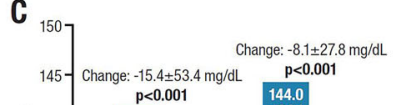

B ${ }_{7.8} 7$ Change $-0.30 .70 .7 \%$

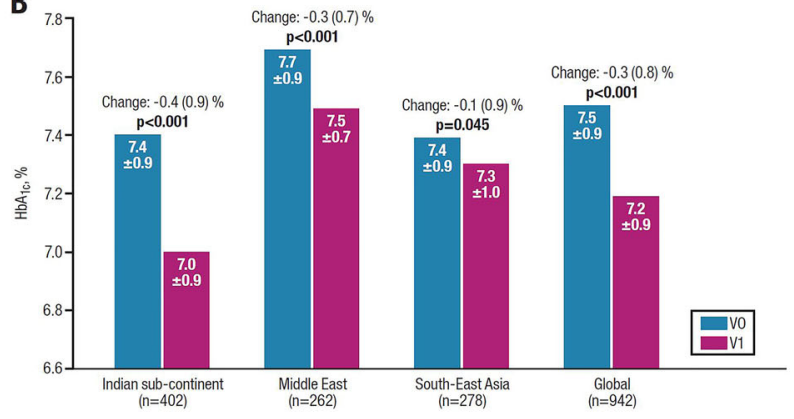

Fig. 2 a Change in weight between V0 and V1 (mean $[\mathrm{kg}] \pm \mathrm{SD}$ ). Mean change was calculated based on patients with values available at V0 and V1. b Change in $\mathrm{HbA}_{1 \mathrm{c}}$ between V0 and V1 (mean [\%] \pm SD). Mean change was calculated based on patients with available data at $\mathrm{V} 0$ and V1. c Change in FPG between V0 and V1 (mean $[\mathrm{mg} / \mathrm{dl}]$ $\pm \mathrm{SD}$ ). Mean change was calculated based on patients

\section{DISCUSSION}

This sub-analysis of the DIA-RAMADAN study analysed the data from the constituent regions in the study-the Indian sub-continent, the Middle East and South-East Asia-representing the diverse cultural and nutritional habits of Muslims worldwide. Overall, the results show that gliclazide MR was safe for patients with type 2 diabetes fasting during Ramadan in the real-world setting. There were relatively few hypoglycaemic events in each region, and none were classed as severe. Effectiveness of gliclazide MR was also similar across regions, with reductions in $\mathrm{HbA}_{1 \mathrm{c}}$, FPG and bodyweight in all regions. These results are in line with the previously reported global analysis [14].

\section{Baseline Characteristics}

Several differences in baseline characteristics among the three regions were noted, and these may influence the slight differences in outcomes observed between the regions. Patients from the Indian sub-continent were generally younger with relatively low BMI $\left(28 \mathrm{~kg} / \mathrm{m}^{2}\right)$, with a high proportion (83\%) being in the IDFDAR moderate/low risk category. In addition, many patients (33\%) were taking $\geq 3$ antidiabetic medications. These factors could have contributed to the large decreases in $\mathrm{HbA}_{1 \mathrm{c}}$ and FPG observed between V0 and V1 for patients from the Indian sub-continent.

Patients in the Middle East showed a higher BMI compared with the other two regions. This is in line with current understanding of obesity in the Middle East, where rates of obesity are high and increasing [17]. This finding is largely 
due to urbanisation and changes in technology leading to a more sedentary lifestyle [17]. In particular, women face more barriers to physical activity, as men have more freedom to exercise and participate in recreational activities $[17,18]$. In the present study, the finding that patients in the Middle East had the greatest reduction in bodyweight is likely linked to the initial high mean bodyweight of this subgroup. Despite having a lower BMI and bodyweight overall, patients in South-East Asia exhibited greater arterial hypertension and dyslipidaemia compared with the other two regions. This is in line with findings regarding the two constituent countries (Malaysia and Indonesia); arterial hypertension has a prevalence of $47.9 \%$ and $34.5 \%$, respectively $[19,20]$, and the estimated prevalence of dyslipidaemia in Indonesian adults is $36 \%$ [21]. Patients from this region were less likely to be advised not to fast compared with the Indian sub-continent and Middle East, although this is likely due to the generally lower IDF-DAR risk category assigned to these patients.

\section{Antidiabetic Treatments}

A relatively high proportion of patients received gliclazide MR in combination with other antidiabetic treatments. Gliclazide MR monotherapy was most widely used in the Middle East region, whereas patients from the Indian sub-continent and South-East Asia tended to receive combinations of antidiabetic treatments. This is in agreement with published survey data indicating that sulphonylureas are commonly used as first-line therapies in the Middle East [22]. Additionally, the mean gliclazide MR dose used in the Middle East was higher than in the other subregions, and more patients in the Middle East were receiving higher gliclazide MR doses (90 mg and $120 \mathrm{mg}$ ) at baseline. Fewer patients from South-East Asia received a combination of three or more antidiabetic treatments. This finding may be reflected in the lower IDF-DAR risk category; this suggests that most patients had well-controlled type 2 diabetes in their physician's opinion, with a mono- or bi-therapy of antidiabetic treatment based on gliclazide MR.

\section{Fasting and Nutritional Habits During Ramadan}

Although many patients broke the fast at some point during Ramadan, particularly in the Indian sub-continent, the relatively low level of symptomatic hypoglycaemia events in all three subgroups suggests that very few of these breaks of fast were for reasons of hypoglycaemia. There are several non-medical reasons that Muslims may be exempted from the Ramadan fast, such as breast-feeding, pregnancy, menstruation or travel. Medical reasons may include dizziness, diarrhoea/vomiting, extreme dehydration and fatigue, as well as any other medical conditions [23]. There are limited data available reporting dietary changes during Ramadan. A recent meta-analysis compared nutritional data from four studies conducted in different regions [24]. Studies from the Greater Middle East region (Algeria and Tunisia) reported increased fat intake and decreased carbohydrate consumption during Ramadan [25, 26]. Studies from South-East Asian countries showed increased and decreased fat intake during Ramadan in Singapore and Indonesia, respectively [27, 28].

In the present study, patients from SouthEast Asia broke fast rarely compared with patients from the Middle East and the Indian sub-continent. However, the three subgroups did not differ greatly in the proportion of patients who broke fast for $>3$ consecutive days. There are several possible explanations for why fewer overall breaks of fast and similar amounts of short breaks of fast ( $\leq 3$ days duration) occurred in the South-East Asian group compared with the other subgroups. Patients from South-East Asian countries consumed more carbohydrates during Ramadan compared with the other two regions, resulting in less need to interrupt the fast because of higher glucose availability. Patients from the Indian subcontinent had a higher IDF risk overall and were more frequently advised not to fast compared with the other regions. The physicians managing these patients may have advised 
breaking fast if necessary because of a greater risk of hypoglycaemia, although this would need to be clarified with further data.

The similarity in short breaks of fast among the three regions may be associated with differences in demographic characteristics. For example, the South-East Asian subgroup was older and had a higher proportion of female patients. This has several potential consequences; first, the proportion of retired and non-active workers in South-East Asia was higher, so there may have been less opportunity for exercise-induced hypoglycaemia. The higher proportion of female patients may result in more frequent breaking of fast due to menstruation, and the presence of a higher proportion of older female patients may further contribute to this because of an increased proportion of menopausal patients.

Changes in dietary habits are highly variable between countries and regions and can be influenced by local customs or religious beliefs. It was not possible to analyse an association between patterns of meal intake at suhoor (predawn meal) and iftar and hypoglycaemic events due to the overall low number of these events in this study; however, this would be an interesting analysis for future studies.

A previous study has noted that dietary habits during Ramadan fall into four categories:

(1) Western-like (fast foods, salt, nuts, potatoes);

(2) high cholesterol and sweet junk foods; (3) Mediterranean-like (vegetables, olive oil, dried fruit); (4) Ramadan-like (soups, legumes, whole grains) [29]. In general, the Mediterranean style diet was considered the healthiest option to maintain during Ramadan. It would be interesting to understand into which diet profile the three regions presented in this study fall.

\section{Safety Outcomes}

As expected from the primary analysis, there were no gliclazide MR-associated adverse events in this study and no severe hypoglycaemic events [14]. Additionally, the occurrence of symptomatic and confirmed hypoglycaemic events remained similarly low between all subgroups, with no group having a particularly high instance of these events. These data support results from other studies conducted in similar regions showing a low risk of hypoglycaemic events in patients treated with gliclazide MR during Ramadan [7, 9, 10]. All three regions also showed significant decreases in weight, with the greatest decrease observed in the Middle East; this is likely due to the high baseline weight in patients from this region. It is important to note that despite the patients receiving gliclazide MR (a sulphonylurea), there is still significant weight loss in this region during Ramadan; this is likely attributable to the Ramadan fast.

\section{Changes in $\mathrm{HbA}_{1 \mathrm{c}}$ and FPG}

Improvements in $\mathrm{HbA}_{1 \mathrm{c}}$ and FPG were observed in all three regions in this study, which is in line with the overall results [14]. It is important to note that the observed improvements may be due to the Ramadan fast itself rather than gliclazide MR treatment, as the present study lacks a control group with patients not receiving gliclazide MR. Similar decreases in $\mathrm{HbA}_{1 \mathrm{c}}$ and FPG were reported in a meta-analysis of 28 observational studies that aimed to assess metabolic profile and hypoglycaemic events in patients with type 2 diabetes during Ramadan [24]. Another study found that patients from Bangladesh, Pakistan and India showed a mean reduction in $\mathrm{HbA}_{1 \mathrm{c}}$ of $0.8 \%$ between pre- and post-Ramadan [30]. The STEADFAST study also reported that patients from the Middle East, Europe and Asia receiving gliclazide and metformin showed decreases in $\mathrm{HbA}_{1 \mathrm{c}}$ and bodyweight when comparing pre- and post-Ramadan values [31]. In the South-East Asian population, FPG did not change significantly. As the numerical change was relatively small with large error margins $(-4 \pm 40.2 \mathrm{mg} / \mathrm{dl})$, this suggests that the subgroup size of patients having a FPG value at V0 and V1 $(n=275)$ was too small to detect any effect. The change in FPG and $\mathrm{HbA}_{1 \mathrm{c}}$ was largest amongst patients from the Indian sub-continent-this is an interesting observation given the increased proportion of dietary carbohydrate (15.2\% more) consumed throughout Ramadan in this 
region. However, it is important to note that the patients from this region were the youngest overall and a high proportion were receiving at least three antidiabetic agents, which may be associate with better glycaemic control overall. The results for $\mathrm{HbA}_{1 \mathrm{c}}$ and FPG are similar to those observed for newer oral antidiabetic agents (DPP4 inhibitors, SGLT2 inhibitors, GLP1 receptor agonists) during Ramadan presented in a recent meta-analysis [32].

\section{Limitations}

There are several limitations associated with this study, including those typically associated with observational and non-comparative study designs. There was no control group not receiving gliclazide $\mathrm{MR}$, so it was not possible to conclude if any of the observed effects on body weight, $\mathrm{HbA}_{1 \mathrm{c}}$ or FPG were due to gliclazide MR treatment. The enrolled patients had already been receiving an established regimen of gliclazide MR for at least 90 days prior to inclusion, implying that the drug was well tolerated in this population. There is also the potential for under-reporting of adverse events and hypoglycaemic episodes due in part to patient self-reporting and recall bias [14]. Analyses of larger patient groups in each of the regions included in this study would potentially yield more robust conclusions, particularly for the South-East Asian region. In addition, the descriptive nature of the study could limit some of the comparisons discussed here.

\section{CONCLUSIONS}

The data from this study indicate that gliclazide MR is safe and effective in maintaining glycaemic control for patients with type 2 diabetes during Ramadan in all three regions studied as part of DIA-RAMADAN, despite cultural and geographical differences among these regions. As anticipated from the primary analysis, no severe hypoglycaemic events or gliclazide MRrelated adverse events were observed in any of the regions during the study [14]. This subanalysis provides additional real-world evidence to support the safety and tolerability of gliclazide $\mathrm{MR}$ in three diverse regions of the world where diabetes is a growing problem due to changing behaviour and dietary habits.

\section{ACKNOWLEDGEMENTS}

The authors would like to thank the patients, their families and all investigators and staff at study sites.

Funding. This study was sponsored by Servier (Servier Affaires Médicales). The Rapid Service Fee for this journal was funded by Servier.

Medical Writing Assistance. Medical writing support was provided by Christopher A Lamb of Physicians World Europe GmbH (Mannheim, Germany), funded by Servier.

Authorship. All named authors meet the International Committee of Medical Journal Editors (ICMJE) criteria for authorship for this article, take responsibility for the integrity of the work as a whole, and have given their approval for this version to be published.

Authors Contributions. MH: acted as international study coordinator; contributed to manuscript preparation and approved the final version for publication. SAS: acted as national study coordinator; contributed to manuscript preparation and approved the final version for publication. SS: acted as national study coordinator; contributed to manuscript preparation and approved the final version for publication. SAR: acted as national study coordinator; contributed to manuscript preparation and approved the final version for publication. JA: acted as national study coordinator; contributed to manuscript preparation and approved the final version for publication. AR: acted as national study coordinator; contributed to manuscript preparation and approved the final version for publication. IS: acted as national study coordinator; contributed to manuscript preparation and approved the final version for publication. MF: acted as national study coordinator; 
contributed to manuscript preparation and approved the final version for publication. WMIWM: acted as national study coordinator; contributed to manuscript preparation and approved the final version for publication. FAA: acted as national study coordinator; contributed to manuscript preparation and approved the final version for publication. AD: analysed data; contributed to manuscript preparation and approved the final version for publication. VC: analysed data; contributed to manuscript preparation and approved the final version for publication. TA: acted as national study coordinator; contributed to manuscript preparation and approved the final version for publication.

Prior Presentation. Preliminary results of this sub-analysis were presented at the European Association for the Study of Diabetes (EASD) 2020 congress.

Disclosures. Thamer Alessa reports grants from Servier Laboratories during the conduct of the study and personal fees from Servier Laboratories, Sanofi-Aventis, Astra Zeneca, Novo Nordisk, Eli Lilly and Novartis outside the submitted work. Shehla Shaikh reports personal fees from Novo Nordisk, Eli Lilly, Novartis, Sanofi-Aventis, Servier and MSD, outside the submitted work. Inass Shaltout reports speaker and advisor roles from Sanofi, Novartis, Lilly, Servier, Astra Zeneca, BI, Takeda, MSD, Bayer, Abbott, Ascensia and Hikma outside the submitted work. Alexandra Durocher and Viviana Cortese are employees of Servier. Mohamed Hassanein, Wan Mohd Izani Wan Mohamed, Md Fariduddin, Fatheya Al Awadi, Javed Akram, Syed Abbas Raza, Saud Al Sifri and Achmad Rudijanto have nothing to disclose.

Compliance with Ethics Guidelines. The study was conducted in accordance with the Declaration of Helsinki. Approval was obtained from the following independent ethics committees or institutional review boards: Conscience Independent Ethics Committee (India, IRB00010059), Drug Regulatory Authority of Pakistan (F.No. 03-01/2019-DD(PS)), Bangladesh Medical Council BMRC/NREC/2016-2019/
933(1-3)), Independent ethics Committees (Sains IRB00010568, Kebangsaan, not available and Malaya, MREC ID No. 2017528-5276) (Malaysia), Dubai Scientific Research Ethics Committee (UAE, DSREC-12/2018_14)), Dasman Institute Ethics Committee (Kuwait, RA/ 054/2019), Institutional Review Board King Fahad Medical City (Saudi Arabia, IRB00010471, FWA00018774), Ministry of Health (Egypt, not available), Badan Pengawas Obat dan Makanan (Indonesia, BPOM128/NKT/III/2019). All patients provided informed written consent to participate in the study.

Data Availability. The datasets used and/or analysed during the current study are available from the corresponding author upon reasonable request.

Open Access. This article is licensed under a Creative Commons Attribution-NonCommercial 4.0 International License, which permits any non-commercial use, sharing, adaptation, distribution and reproduction in any medium or format, as long as you give appropriate credit to the original author(s) and the source, provide a link to the Creative Commons licence, and indicate if changes were made. The images or other third party material in this article are included in the article's Creative Commons licence, unless indicated otherwise in a credit line to the material. If material is not included in the article's Creative Commons licence and your intended use is not permitted by statutory regulation or exceeds the permitted use, you will need to obtain permission directly from the copyright holder. To view a copy of this licence, visit http://creativecommons.org/licenses/by$\mathrm{nc} / 4.0 /$.

\section{REFERENCES}

1. International Diabetes Federation. IDF diabetes atlas-9th edition. Brussels: International Diabetes Federation; 2019.

2. Lee JY, Wong CP, Tan CSS, Nasir NH, Lee SWH. Type 2 diabetes patient's perspective on Ramadan 
fasting: a qualitative study. BMJ Open Diabetes Res Care. 2017;5:e000365.

3. Al-Arouj M, Assaad-Khalil S, Buse J, Fahdil I, Fahmy $\mathrm{M}$, Hafez $\mathrm{S}$, et al. Recommendations for management of diabetes during Ramadan: update 2010. Diabetes Care. 2010;33:1895-902.

4. Hassanein M, Al-Arouj M, Hamdy O, Bebakar WMW, Jabbar A, Al-Madani A, et al. Diabetes and Ramadan: practical guidelines. Diabetes Res Clin Pract. 2017;126:303-16.

5. Salti I, Benard E, Detournay B, Bianchi-Biscay M, Le Brigand $\mathrm{C}$, Voinet $\mathrm{C}$, et al. A population-based study of diabetes and its characteristics during the fasting month of Ramadan in 13 countries: results of the epidemiology of diabetes and Ramadan 1422/2001 (EPIDIAR) study. Diabetes Care. 2004;27:2306-11.

6. Sola D, Rossi L, Schianca GP, Maffioli P, Bigliocca $\mathrm{M}$, Mella R, et al. Sulfonylureas and their use in clinical practice. Arch Med Sci. 2015;11:840-8.

7. Al Sifri S, Basiounny A, Echtay A, Al Omari M, Harman-Boehm I, Kaddaha G, et al. The incidence of hypoglycaemia in Muslim patients with type 2 diabetes treated with sitagliptin or a sulphonylurea during Ramadan: a randomised trial. Int J Clin Pract. 2011;65:1132-40.

8. Al-Arouj M, Hassoun AA, Medlej R, Pathan MF, Shaltout I, Chawla MS, et al. The effect of vildagliptin relative to sulphonylureas in Muslim patients with type 2 diabetes fasting during Ramadan: the VIRTUE study. Int J Clin Pract. 2013;67: 957-63.

9. Aravind SR, Ismail SB, Balamurugan R, Gupta JB, Wadhwa T, Loh SM, et al. Hypoglycemia in patients with type 2 diabetes from India and Malaysia treated with sitagliptin or a sulfonylurea during Ramadan: a randomized, pragmatic study. Curr Med Res Opin. 2012;28:1289-96.

10. Aravind SR, Al Tayeb K, Ismail SB, Shehadeh N, Kaddaha G, Liu R, et al. Hypoglycaemia in sulphonylurea-treated subjects with type 2 diabetes undergoing Ramadan fasting: a five-country observational study. Curr Med Res Opin. 2011;27: 1237-42.

11. Avogaro A. Treating diabetes today with gliclazide MR: a matter of numbers. Diabetes Obes Metab. 2012;14(Suppl 1):14-9.

12. Schernthaner G, Grimaldi A, Di Mario U, Drzewoski J, Kempler P, Kvapil M, et al. GUIDE study: Doubleblind comparison of once-daily gliclazide MR and glimepiride in type 2 diabetic patients. Eur J Clin Invest. 2004;34:535-42.
13. International Diabetes Federation and Diabetes and Ramadan. IDF-DAR practical guidelines. Brussels: International Diabetes Federation and Diabetes and Ramadan; 2021.

14. Hassanein M, Al Sifri S, Shaikh S, Abbas Raza S, Akram J, Pranoto A, et al. A real-world study in patients with type 2 diabetes mellitus treated with gliclazide modified-release during fasting: DIARAMADAN. Diabetes Res Clin Pract. 2020;163: 108154

15. Laborotoires Servier. Diamicron $80 \mathrm{mg}$ tabletssummary of product characteristics. Suresnes: Laborotoires Servier; 2020.

16. American Diabetes Association. 2. Classification and Diagnosis of Diabetes: Standards of Medical Care in Diabetes-2019. Diabetes Care. 2019;42: S13-28.

17. Kilpi F, Webber L, Musaigner A, Aitsi-Selmi A, Marsh T, Rtveladze K, et al. Alarming predictions for obesity and non-communicable diseases in the Middle East. Public Health Nutr. 2014;17:1078-86.

18. Alnohair S. Obesity in gulf countries. Int J Health Sci (Qassim). 2014;8:79-83.

19. Abdul-Razak S, Daher AM, Ramli AS, Ariffin F, Mazapuspavina MY, Ambigga KS, et al. Prevalence, awareness, treatment, control and socio demographic determinants of hypertension in Malaysian adults. BMC Public Health. 2016;16:351.

20. Turana Y, Tengkawan J, Soenarta AA. Asian management of hypertension: Current status, home blood pressure, and specific concerns in Indonesia. J Clin Hypertens (Greenwich). 2020;22:483-5.

21. Lin C-F, Chang Y-H, Chien S-C, Lin Y-H, Yeh H-Y. Epidemiology of dyslipidemia in the Asia Pacific Region. Int J Gerontol. 2018;12:2-6.

22. Al-Maatouq M, Al-Arouj M, Assaad SH, Assaad SN, Azar ST, Hassoun AA, et al. Optimising the medical management of hyperglycaemia in type 2 diabetes in the Middle East: pivotal role of metformin. Int J Clin Pract. 2010;64:149-59.

23. Hassanein M, Echtay A, Hassoun A, Alarouj M, Afandi B, Poladian R, et al. Tolerability of canagliflozin in patients with type 2 diabetes mellitus fasting during Ramadan: results of the Canagliflozin in Ramadan Tolerance Observational Study (CRATOS). Int J Clin Pract. 2017;71:e12991.

24. Tahapary DL, Astrella C, Kristanti M, Harbuwono DS, Soewondo P. The impact of Ramadan fasting on metabolic profile among type 2 diabetes mellitus patients: a meta-analysis. Diabetes Metab Syndr. 2020;14:1559-70. 
25. Khaled BM, Belbraouet S. Effect of Ramadan fasting on anthropometric parameters and food consumption in 276 type 2 diabetic obese women. Int J Diabetes Dev Ctries. 2009;29:62-8.

26. Sfar H, Sellami S, Boukhayatia F, Naceur K, Mami F. Biochemical, physiological and body composition changes in patients with type 2 diabetes during Ramadan fasting. Ibnosina J Med Biomed Sci. 2017;9:164-8.

27. Gustaviani R, Soewondo P, Semiardji G, Sudoyo AW. The influence of calorie restriction during the Ramadan fast on serum fructosamine and the formation of beta hydroxybutirate in type 2 diabetes mellitus patients. Acta Med Indones. 2004;36: 136-41.

28. Yeoh EC, Zainudin SB, Loh WN, Chua CL, Fun S, Subramaniam T, et al. Fasting during Ramadan and associated changes in glycaemia, caloric intake and body composition with gender differences in Singapore. Ann Acad Med Singap. 2015;44:202-6.
29. Shadman Z, Poorsoltan N, Akhoundan M, Larijani B, Soleymanzadeh M, Akhgar Zhand C, et al. Ramadan major dietary patterns. Iran Red Crescent Med J. 2014;16:e16801.

30. Zargar AH, Siraj M, Jawa AA, Hasan M, Mahtab H. Maintenance of glycaemic control with the evening administration of a long acting sulphonylurea in male type 2 diabetic patients undertaking the Ramadan fast. Int J Clin Pract. 2010;64:1090-4.

31. Hassanein M, Abdallah K, Schweizer A. A doubleblind, randomized trial, including frequent patientphysician contacts and Ramadan-focused advice, assessing vildagliptin and gliclazide in patients with type 2 diabetes fasting during Ramadan: the STEADFAST study. Vasc Health Risk Manag. 2014;10:319-26.

32. Gad H, Hayat T, Al-Muhannadi H, Malik BR, Mussleman P, Malik RA. Efficacy and safety of the newer oral hypoglycemic agents in patients with T2DM during Ramadan: a systematic review and metaanalysis. Diabetes Res Clin Pract. 2021;172:108562. 